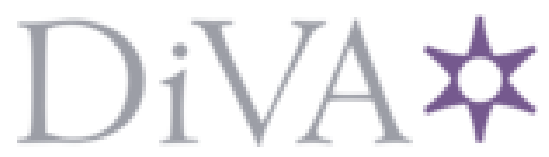

http://www.diva-portal.org

This is the published version of a paper published in Vård $i$ Norden.

Citation for the original published paper (version of record):

Benderix, Y., Nordstrom, B., Nyberg, P., Sivberg, B. (2009)

Staff members views of the work climate in sheltered homes for adults with Autism Spectrum

Disorders.

Vård i Norden, 29(2): 38-41

Access to the published version may require subscription.

N.B. When citing this work, cite the original published paper.

Permanent link to this version:

http://urn.kb.se/resolve?urn=urn:nbn:se:lnu:diva-30713 


\title{
Staff members' views of the work climate in sheltered homes for adults with Autism Spectrum Disorders
}

\author{
Ylva Benderix, PhD, Lecturer - Berit Nordstrom, PhD, Senior Lecturer - Per Nyberg PhD, Senior Lecturer - Bengt Sivberg, PhD, \\ Associate Professor
}

\begin{abstract}
The mean scores of the Creative Climate Questionnaire for 152 staff members working in 58 sheltered homes for individuals with autism were rated closer to creative than to stagnant organizations. There was a significant difference between two types of settings. In sheltered homes, the persons with autism had their daily activity outside the home. Here staff members had higher scores in all creative dimensions compared to homes with daily activities. Staff in sheltered homes, where the residents leave the premises for their daily work or activities, perceived the work climate as significantly more creative and satisfying.
\end{abstract}

KEYWORDS: Autism, staff, work climate, sheltered homes

\section{Introduction}

There are few studies investigating staff members' experience of the work climate in sheltered homes for persons with Autism Spectrum Disorders (ASD). Lundstrom (1) investigated the influence of work climate for experiences of strain among staff working in sheltered homes. He found that the staff was exposed to violence from the persons living in the sheltered homes, and that staff needed support when violence had occurred. Lundstrom suggested that there are two factors related to staff's experience of liability, their experience of the work climate (2) and their personality. Blacher and McIntyre (3) investigated syndrome specificity and behavioural disorders in young adults with intellectual disability. The results showed that autism led to the highest scores in the area of multiple behavioural problems. Staff described high levels of stress (4) using a self-reported questionnaire to measure stress, burnout, attribution, emotions, optimism and helping behaviour in response to challenging behaviour, although this did not appear to relate to their thoughts and feelings about challenging behaviour. A Swedish study (5) investigated staff members' views of working in a sheltered home for children with autism and intellectual disabilities. They found that staff were highly ambitious, strongly committed to their work as well as to the children and their families. Questions of safety were also raised, as staff members were frequently exposed to violent and sometimes dangerous behaviour.

The Creative Climate Questionnaire (CCQ) was used to rate the psychological climate in 13 long-term care clinics (6). The results revealed positive relations between a creative climate in the work place and the quality of care. An investigation by Norberg et al. (7), which employed the CCQ to study sheltered homes for patients with dementia, revealed that staff spent considerably more time together with the patients in the sheltered homes assessed as having the most creative climate. Due to the increased emphasis on people's work adjustment in society, it is essential to identify specific constructs that can facilitate this adjustment. One such construct is Antonovsky's (8) sense of coherence, which is based on the assumption that the world is comprehensible, manageable and meaningful. It can be assumed that an individual's sense of coherence would have a moderating effect on his or her work adjustment by strengthening or weakening the level and quality of his or her interaction with the environment (9). Feldt (10) suggests that individuals with high SOC scores enjoy better health and well being as well as avoiding work stress and the resulting burnout more often than those with low SOC sco- res. The SOC questionnaire has been used worldwide and seems to be a reliable and valid instrument that can be applied across cultures in order to measure how people cope with stressful situations and still remain healthy (11).

\section{Aim}

The aim of this study was to explore staff members' views of the working climate in sheltered homes for adults with Autism Spectrum Disorders and additionally staffs' sense of coherence.

\section{Method}

Participants and procedure

125 sheltered homes were drawn from the list of homes in a national database of municipal services for persons with ASD. An introductory letter and five copies of the questionnaire were sent to each sheltered home in order to reach all staff members. Ten homes had been closed by the municipality and 17 were excluded due to not having any staff members individually responsible for persons with ASD. No data was gathered from 40 sheltered homes (39\%), either because of refusal to participate (confidential reasons or lack of time), or failure to return the questionnaire. A total of 152 staff members (101 women, 45 men and 6 who did not disclose their sex) from the remaining 58 homes returned completed questionnaires. The 58 homes were spread all over the country, and were both provincially and city situated.

In Sweden, persons with ASD live in sheltered accommodation comprising five or six adults with one staff member taking care of two clients. Two parallel systems exist: Sheltered homes ( $\mathrm{SH})$ where residents leave the home every day to engage in work or activities and sheltered homes with activity (SHA) where residents do not leave the home to participate in activities.

\section{Measures}

Measures included staff demographics, such as gender, age, educational level, autism training and type of work place. Two instruments were used in order to rate staffs' view of work climate and their sense of coherence. The Creative Climate Questionnaire (CCQ) was developed during the 1980s within the scope of a research programme on the subject of organizational conditions (12). The reliability of the CCQ as indicated with Crohnbach's alpha was satisfactory in several studies $>0.80(13,14)$. The instrument includes 50 items, 5 for each of the 10 dimensions: Challenge/Motivation (How challenged, emo- 


\section{Table 1 Description of the study sample}

\begin{tabular}{|l|c|c|c|c|c|c|}
\hline & \multicolumn{3}{|c|}{ Working place } & \multicolumn{3}{c|}{ Gender } \\
\hline & SH & SHA & p-value & Female & Male & p-value \\
\hline Age, mean (sd) & $39.4(11.1)$ & $39.1(10.6)$ & .422 & $39.7(11.0)$ & $39.4(10.7)$ \\
\hline Female staff (\%) & 81.4 & 61.3 & .011 & - & - & .861 \\
\hline University degree (\%) number & 21.1 & 17.6 & .615 & 22.4 & 15.4 & .355 \\
\hline Autism training (\%) number & 23.0 & 27.7 & .518 & 29.7 & 20.0 \\
\hline Sense of Coherence mean (sd) & $148.1(18.9)$ & $143.0(19.5)$ & .114 & $143.8(21.1)$ & $146.0(18.3)$ & .544 \\
\hline *CQ mean, sd & $17.5(4,3)$ & $16.2(4.2)$ & .095 & $16.8(4.5)$ & $16.7(3.8)$ \\
median, (IQR) & $18.0(6.8)$ & $16.4(5.7)$ & .076 & $17.4(6.6)$ & $16.7(6.0)$ \\
\hline
\end{tabular}

* Conflict excluded

tionally involved, and committed the staff is), Freedom (The amount of freedom staff members have to make decisions regarding their work), Idea-support (The resources available for implementing new ideas), Trust/Openness (Whether staff members trust each other sufficiently to deal openly with differences of opinion and whether communication is open and honest), Dynamism/Liveliness (The amount of variety in the organisation) Playfulness/Humour (Whether and to what degree a playful and informal atmosphere exists in the workplace), Debate (The degree to which staff members engage in lively debate about issues), Conflicts (The degree to which people engage in interpersonal conflicts or «warfare»), Risk-taking (The degree to which staff members dare to take initiatives, even if the outcome is uncertain) and Idea-time (How much time staff members have to think through and discuss new ideas). Ekvall (2) categorised a representative sample of 27 different organizations as innovative, stagnant and average, where innovative referred to the ability to develop and stagnant to an inability to handle new challenges. A high CCQ value indicates a creative climate, except in the case of conflicts, where the reverse applies (12). A non-creative climate could have a negative influence on the well-being of patients in sheltered accommodation because they obtain less help and stimulation from staff (7). Creative organizations with clear aims, a collaborative leadership and an open work climate are health factors for staff members (13).

The SOC Scale (8) was used to measure staff members' sense of coherence (14). The theory and questionnaire were developed to illuminate how people manage their lives despite high levels of stress (11). In the questionnaire, the 29 items are rated on a seven-point Likert scale (never-very often) and comprise three main components; comprehensibility, manageability and meaningfulness. The possible scores range from 29 to 203. Antonovsky's hypothesis was that the higher the score, the stronger the SOC, and the more likely a person will be to cope successfully with stressful life situations. In a study, Langius et al. (15) proposed that the sense of coherence concept provides a sound theoretical basis both for studying and strengthening the caring component in clinical practice. The SOC was administered to five Swedish samples (3 groups of nurses, patients in a hospital and a general population sample). A Self-Motivation Inventory (SMI) and the Karolinska Scales of Personality (KSP) were used to test the relation between the SOC and personality traits. The results revealed that those with a strong SOC also exhibited higher general motivation, less Hostility as well as less Somatic and Psychic Anxiety. The reliability of the SOC as indicated with Crohnbach's alpha was $>0.77$ in a Swedish population study with 145 participants (17). The 29 item scale has proved to be psychometrically sound and reliable in Hebrew and English (8) as well as in Swedish (15).

Data analysis

Statistical analyses were conducted using SPSS, version 11.5 (SPSS Inc. 2001). Student's t-test was used for comparisons between groups and Spearman's correlation coefficient for analysis of covariation between SOC and CCQ scores for variables that were deemed to be normally distributed (age and SOC). The Mann-Whitney U-test was employed for analyses of differences between groups in relation to CCQ.

\section{Ethical considerations}

This study was approved by the Ethics Committee at the Faculty of Medicine, Lund University (LU 304-99). Potential participants were informed about the study in a covering letter sent with the questionnaires. Informed written consent was provided by the respondents.

\section{Results}

\section{Staff characteristics}

There were a significantly higher proportion of women employed in SHs than in SHAs. Apart from that, no differences related to age, educational background, autism training or SOC were found between $\mathrm{SH}$ and SHA. Nor were any significant differences found between male and female staff regarding age, educational level or specific autism training (Table 1). Age was significantly higher among staff with autism training than among those who did not have such a qualification (42.6 vs 38.6; $\mathrm{p}=.047)$.

\section{Staff members' views of the work climate}

Based on Ekvall's definition (2), the working climate indices for both types of sheltered home were closer to creative/innovative than to stagnant organizations, as can be seen in Figure 1. There was, however, a significant difference in the Challenge/motivation dimension between SHs (median 2.20, IQR .80) and SHAs (1.94, IQR .60) $(\mathrm{p}=0.005)$. There was also a significant difference in the Conflict dimension between SHs (median .82, IQR 1.0) and SHAs (median 1.0, IQR .80) $(\mathrm{p}=0.049)$.

\section{Staff members' sense of coherence}

Correlation analysis of the sample revealed no relation between SOC and CCQ. The mean level of SOC for all participants in this study was 144. There were no significant gender differences, the mean level for women being 142 and for men 147, nor any significant differences in relation to type of work place, the mean score in SHs being 147 and in SHAs 143 (Table 1). The mean level for those trained in autism was 146, compared to 144 for those with no special training. The group with a university degree had a significantly higher SOC score compared to those with a lower educational level (152 vs. 142; $\mathrm{p}=.012$ ).

\section{Discussion}

Out of 125 identified sheltered homes, 58 returned questionnaires completed by 152 individuals. Due to the lack of detailed information about the number of staff working with persons with autism more 


\section{Figure 1: Work climate in sheltered homes in relation to creative and stagnant organizations}
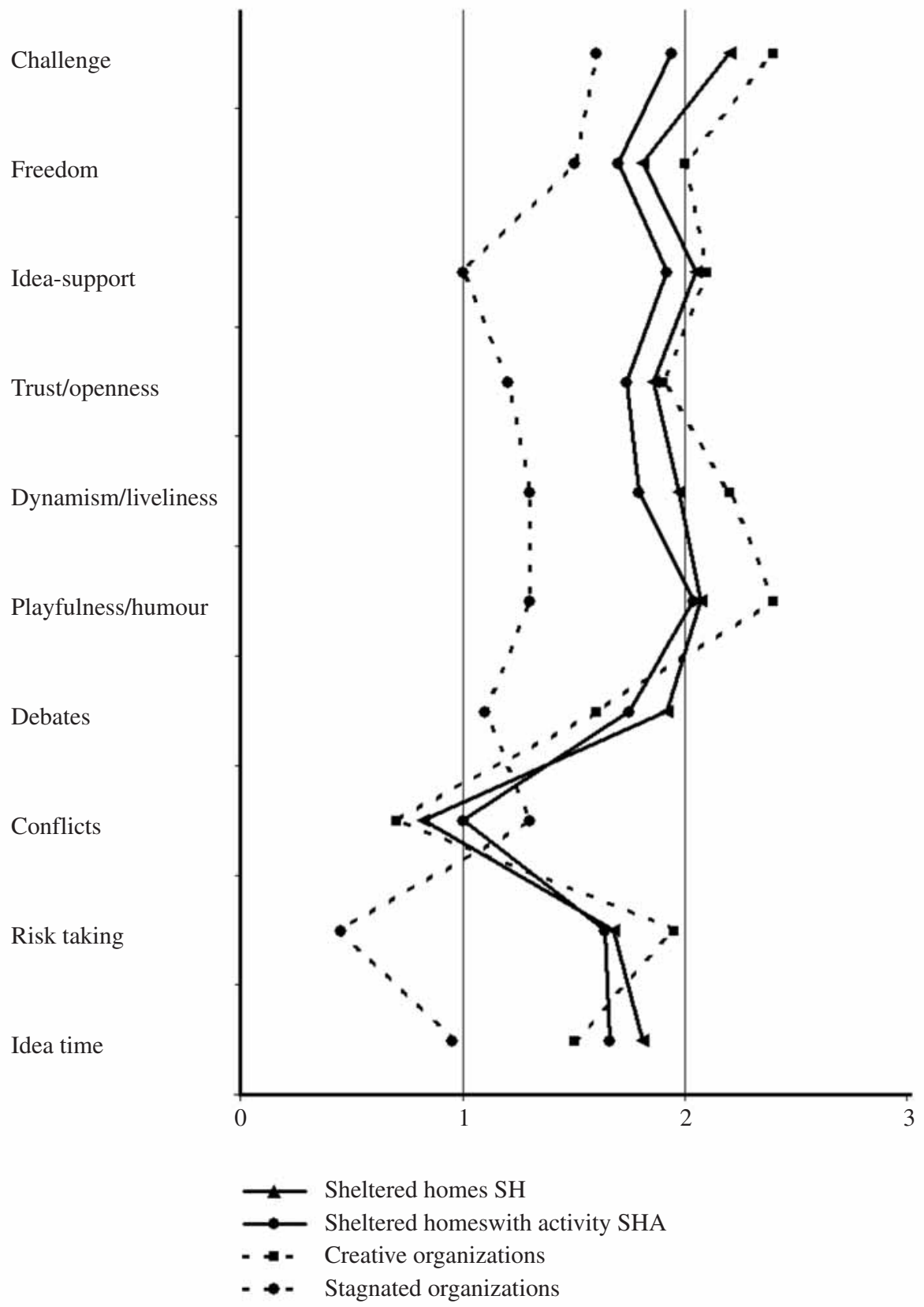

sheltered homes are very committed $(20,5)$. Since previous research has shown that job satisfaction is linked to service quality (21), the findings highlight the need for further research on the subject of staff satisfaction.

In this study, staff members in sheltered homes with activity (SHA) seemed to experience more conflicts, perhaps as a result of challenging behaviour. Since some persons with autism have the highest scores in the area of multiple behaviour problems as challenging behaviour (3), it could be difficult for them to find activities outside the sheltered home.

In light of some studies suggesting that staff members are exposed to violence (1) and that stress has a negative impact on staff members' helping behaviour (4), there is a need for more studies in sheltered accommodation for persons with autism who for different reasons are excluded from work or other activities in society.

\section{Acknowledgements:}

We want to thank the staff members' participation in the study for their time answering the questionnaires and the Vardal Foundation for the funding.

Ylva Benderix, Berit Nordstrom, Per Nyberg and Bengt Sivberg, Health Sciences, Faculty of Medicine, Lund University, Sweden.

Corresponding author: Ylva Benderix, School of Education, Department of Special and Therapeutic Pedagogy, Växjö University, 35195 Växjö, Sweden.

Ylva.Benderix@vxu.se

\section{References}

1. Lundström, M. (2006) Våld, utmaning och utmattning. Thesis, Umeå University, Sweden.

2. Ekvall, G. (2004) Creative organizational climate. Ekvall, Organisationspsykologi, Stockholm.

3. Blacher, J. \& McIntyre L. (2006) Syndrome specificity and behavioural disorders in young

intensity in each of the 125 sheltered homes, we were unable to calculate the participation rate. However, the aim of the study was to identify factors possibly associated with the work climate in sheltered homes for persons with autism.

There is nevertheless a risk that differences in views on work climate exist between those who participated in the study and those who did not. The 58 homes represented in the study as well as those that failed to respond or did not meet the inclusion criterion were spread all over Sweden. Thus, while the sample may be considered representative, self-reported instruments of experiences and attitudes are limited to what individuals are willing to disclose (18). Questions may be misunderstood, although the use of an instrument with several dimensions each of which contains a number of items reduces the risk of misunderstanding and no single question is of decisive importance for the result (19).

In all work places it is important to discuss experience of the work climate and job satisfaction. In this study, one major finding is that most staff members experienced the work climate as more similar to that in creative/innovative work places (12). Many staff members in adults with intellectual disability: cultural differences in family impact. Journal of Intellectual Disability Research, 3, 184-198.

4. Rose, D. \& Rose, J. (2005) Staff in services with intellectual disabilities: the impact of stress on attributions of challenging behaviour. Journal of Intellectual Disability Research, 49, 827-838.

5. Benderix, Y., Nordstrom, B., Sivberg, B. (2009) Staff member's experience of work in a sheltered home for children with autism. Manuscript submitted for publication.

6. Mattiasson, A-C. (1995) Autonomy in nursing home settings. Stockholm: Karolinska Institutet.

7. Norbergh, KG., Hellzén, O., Asplund, K. \& Sandman, PO. The relationship between organizational climate and the content of daily life for people with dementia living in group-dwelling, Journal of Clinical Nursing, 2002, 11, 237-246.

8. Antonovsky, A. (1987) The mystery of health. Natur och Kultur. Stockholm.

9. Strauser, D.\& Lustig, D. (2003) The moderating effect of sense of coherence on work adjustment. Journal of Employment Counselling. http:goliath.ecnext.com. Publication date: 03-sept-03.

10. Feldt, T. (2004) Sense of coherence and work characteristics: A cross-lag- 
ged structural equation model among mangers. Journal of Occupational and Organizational Psychology. Puplication date September 2004.

11. Eriksson, M. \& Lindström, B. (2005) Antonovsky's sense of coherence scale and the relation with health: a systematic review. Journal of Epidemiological Community health, 59, 460-466.

12. Ekvall, G. (1986). Manual formulär A: Arbetsklimat (GEFA).

13. Laurer, K. (1994) The assessment of Creative Climate: An investigation of The Ekvall Creative Climate Questionaire. Buffalo: State University Collage of Buffalo.

14. Talbot, R., Cooper, C. \& Barrow, S. (1992) Creativity and stress. Creativity and Innovation Management, 1, 183-193.

15. Hansson, K. \& Cederblad, M. (1995) Känsla av sammanhang. Sense of Coherence 6. Lund: Institutionen för Barn och Ungdomspsykiatri, Lund University.

16. Langius, A., Björvell, H. \& Antonovsky, A. (1992) The Sense of Coherence Concept and its Relation to Personality Traits in Swedish Samples. Scandinavian Journal of Caring Science, 6, 165-171.

17. Langius, A. \& Björvell, H. (1993) Coping ability and functional status in a Swedish population sample. Scandinvian Journal of Caring Science, 7, 3-10.

18. SPSS Base 11.0 User's Guide, SPSS Inc, 2001. Chicago.

19. Polit, D. \& Hungler, B.(1995) Nursing Research, Principles and Methods, 5th ed, p167. J.B. Lippincott Company, Philadelphia.

20. Spector, P.E. (1992) Summerated rating scale constructions: An introduction, pp. 1-72. Sage University Paper Series on Quantitaive Applications in the Social Sciences, Newbury Park, CA.

21. Ford, J. \& Honnor, J. (2000) Job satisfaction of community residential staff serving individuals with severe intellectual disabilities. Journal of Intellectual \& Developmental Disability, 25, 343-362.

22. Snipes, R., Oswald, S., LaTour, M., Armenakis, A. (2005) The effects of specific job satisfaction facets on customer perceptions of service quality: an employee-level analysis. Journal of Business Research, 10, 1330-1339. 